\title{
The Political Field in the Operational Area
}

Abstract This chapter deals with one possible implementation of field theory in a generic operational area. The main challenge is to operationalise the concept of field-specific capital in order to classify and affect the adversary and other actors on the field.

Keywords Operationalisation · Field specific $\cdot$ Actors

The classic Western definition of war reads: "the continuation of politics by other means". This definition should be kept in mind when dealing with the armed groups in the area, as well as the civilian political structure, regardless of the form or level of violence prevalent on the field at the time. If the local field rules and recognised forms of capital can be identified, then the chances of being able to make effective decisions will increase dramatically.

For example, patterns of behaviour can be monitored to predict future activity at a strategic level and below. These predictions gain further credence when the intervention forces actively use their knowledge to bring about structural change to the logic being applied in the operations area; it is not just a question of observing. It is pertinent here to

${ }^{1}$ von Clausewitz (1991, p. 42).

(C) The Author(s) 2017

H. Gunneriusson, Bordieuan Field Theory as an Instrument for Military Operational Analysis, New Security Challenges, DOI 10.1007/978-3-319-65352-5_3 
remember that this is an empirical science. The theoretical framework given presents a method of reflecting on and an approach to the mission in hand. What in reality actually applies and has import on the field is beyond the scope of this theory; the theory must be developed heuristically. This can be achieved by conducting various types of InfOps (Information Operations), such as HUMINT (Human Intelligence). Strategies on the field are all a type of reproduction strategy, the essential being to maintain or improve one's own or the group's position on the field. In short, it is a question of power. Conversion strategies aimed at changing one form of capital to another, which in a given situation appears more advantageous, are one example.

In an area plagued by unrest, the political field may be likened to a piece of sloping ground where actors believe that they must use violence to have any influence, thereby foregoing more civilised political methods. In general terms, one can say that the ultimate goal in the struggle on the field is dominance. Dominance is achieved by the actors who have acquired a considerable amount of the current marketable symbolic capital on the field (e.g. capacity for violence, ability to call mass meetings and religious legitimacy), often manifested by occupying important positions (e.g. as leader of a particular group or organisation). The shape of the field will reflect the values of the dominant group or groups. A field presupposes a conflict, which then defines the arena. All actors believe the political game to be worth playing. This is a prerequisite to qualify as an actor, but the actors hold different viewpoints and apply different methods. The presence of a number of institutions that can dispense awards within the field raises the stakes for conflict on the field. These may be state institutions, but they may also be informal institutions such as various groupings (military, ethnic, religious, geographic, etc.).

The international force will have as a goal the establishment of a monopoly of the use of force in the operations area. This will mean that several of the actors on the field will have their positions threatened. To merely meet these actors with force will compel them to go underground, which is not a step towards a desired end state. The desired effect in the local political field of the operations area is that all political activity is conducted within the framework defined by the politicostrategic goals of which the intervention force is a product. Groups which have an ulterior political agenda, beyond violence, will be inclined to reappraise their strategies if the alternative is marginalisation, or the threat of their organisation ceasing to exist. Marginalisation in this sense 


\section{Considerable amount of capital} (power)

\section{Political activity using civil political means; accepted practice}

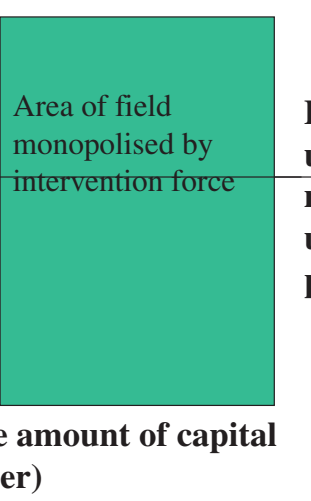

Fig. 3.1 A field sketch used as a mind map. Actors on the right side of the field will, by the use of both the carrot and the stick, be made to change their strategies to ones more akin to those on the left side of the field

is primarily political, but social or economical marginalisation can be critical vulnerabilities to weaken their political capital. This inclination is one of the two crucial factors which make it important to influence these actors who can choose in particular. The other important factor is that actors with a political agenda find it easy to assert legitimacy for their actions, in contrast to the bandit gangs and warlords with limited political aims and little choice other than marginalisation (Fig. 3.1).

Different types of groupings can offer various types of reward, both formal and informal. For example, money or a promise of a position in the present or future government hierarchy may be offered. However, some driving forces may be less easily identifiable. As a rule, driving forces are harder to identify if they involve cultural phenomena that are not easily recognisable within one's own political culture. It is in these obscure peculiarities that there lies a potential source of great error with regard to one's choice of course of action in the operations area. Power in one form or another is what is respected on the field, even if that power is of an indirect nature. The specific initial empirical question in any study is: What constitutes power in this situation?

Each field has its own specific characteristics, even if all fields have certain common basic structures that enable field theory to be applied 
in different areas. ${ }^{2}$ For example, the French intellectual field cannot be studied without recognising the importance afforded to a few so-called elite schools throughout the country. A country such as the former Yugoslavia had the particular characteristic that the distinctive quality of each of the regions was much more pronounced than in many other countries, which was then reflected in the political field. A picture of the field can be gained by studying how actors and institutions interact with each other. The relative conditions guided the actors' strategies, which in turn served to preserve or alter the strength of the field's various forms of power. ${ }^{3}$ The power of the individual actor on the field is relative to the remainder of the field, which means that a stronger position is attained if the capital of one's opponent is devalued, and his power thus reduced.

The model of thought is simple in itself, but it is important to do more than just understand it. It should be seen as an approach or link to reality that quickly enables one to organise and structure the actors in an operations area. As a result, the model offers a guide to the courses of action open and to what may be appropriate in any given situation. Acting in accordance with field theory at the operational level requires one to focus on three main tasks, of which one can be considered the one that distinguishes the method of attack from other more conventional alternatives.

\section{A Tentative Checklist}

Initially one can say that the checklist should be seen as focused on structural change first. This will give collateral effects on the actors which are directly affected by the structural change and secondary effects on the actors, who are not directly involved in the practice being targeted, but still are a part of the social field and takes notes on what happens on it.

\section{Secure a monopoly on armed force}

This is the minimum and basic demand placed on the intervention force. If the politico-strategic goals are reasonably modest, then the area of operations may be limited to an area smaller than the whole conflict arena. Bosnia provides a good example, when for a long time the

\footnotetext{
${ }^{2}$ For several examples of field studies, see Broady (1998).

${ }^{3}$ Bourdieu (1996, p. 159).
} 
Bosnian Serbs were allowed to control their own areas because there were insufficient resources to contain their capacity for violence.

2a. Establish an understanding of the logic of practice in the operations area

This is the structural approach, which deals with making out what is considered of value on this social field, what is generating capital, both symbolic and economical capital, perhaps even social capital.

2b. Establish the agendas of key actors

This applies in particular to those who perpetrate violence: Which of them have political goals which can be achieved by means other than violence? Those that have this type of goal are potentially able to change their approach to a political agenda without violence. In addition, those actors who have a political agenda but who do not use violent means must be identified. All of these actors must be accessible for dialogue and qualitative intelligence work.

\section{Work on what are considered the critical points of the logic of practice}

This is most likely a heuristic process, where the targets and goals change during the process as new learnings most likely will submerge the more you deal with the social field of the operational field. One example of what one can target is the way religion is used as a means of mobilisation of violence. Another example can be the informal economy of the social field, how to tweak it to get the actors into perceiving other (more benevolent) strategies as "the best" strategies, or at least better than the strategies their own forces regard as unwanted. Furthermore, the symbolic capital of social, geographical or ethnic groups, even gender, can be can be targeted-strengthening or weakening their positions in order to achieve certain effects on the way the social field is constituted.

\section{4a. Offer actors using violent tactics the opportunity to change strategy}

Once an acceptable monopoly on armed force has been established and has been in operation for a while, negotiations with the actors should begin. In short, resources are offered to allow participation in the political process, but using peaceful means. The choice of resources will vary and will be guided by the actors' needs, and may involve both material and services. Reconstruction is thus not something that takes place after the conflict. Reconstruction of whatever is involved provides a route to gaining control over the area of operations; it is not something that happens through the process of establishing control. The military force 
must therefore direct the process of reconstruction in the area, partly because it is an integral part of their operational plan as discussed here, and partly because it would be a dangerous undertaking for NGOs to operate without the protection of the military force.

\section{4 b. Offer resources to political actors not using violent tactics}

There should be a carrot for political actors with an existing peaceful agenda. It is, however, just as important to have a stick ready for the actors using violent methods who refuse to change their strategy. They will see their political influence wane at the same time that the political party apparatus of politicians using peaceful means and its ability to reach out will grow, and that the military force continues to hinder the agenda of violent political elements. The offer at (3a) remains open for those who wish to take it up. It is a question of showing which practices will lead to increased power, violence probably having been the most advantageous prior to the military force initiating their operational plan.

It is important at this point to stress that those who receive political help are at liberty to disagree with the politics pursued by the countries represented within the military force. Under no circumstances should it appear that those receiving help have been bought up by a foreign power. Their symbolic capital should not be undermined, which will be the case if those receiving support are perceived as nothing but puppets of the contributing nations of the military force. The ideal situation would be to have the military force supporting a group comprising different collective actors covering a wide political spectrum. These actors would then become the foundation for the remodelled political field. Through the strengthening of these actors, the political field will be redefined, leading to the actors inclined to violence being marginalised. In the end, if these actors do not change strategy, they will be perceived-not only by the international force but also more importantly by the population - as terrorist organisations opposing the civil political system.

\section{BiBLIOGRAPHY}

Bourdieu, P. (1996). Homo academicus. Eslöv: Symposion.

Broady, D. (1998). Kulturens fält. En antologi. Göteborg: Daidalos.

von Clausewitz, C. (1991). On war. http://www.gutenberg.org/files/1946 /1946-h/1946-h.htm [Visited 170320]. 
Open Access This chapter is licensed under the terms of the Creative Commons Attribution 4.0 International License (http://creativecommons.org/licenses/ by $/ 4.0 /$ ), which permits use, sharing, adaptation, distribution and reproduction in any medium or format, as long as you give appropriate credit to the original author(s) and the source, provide a link to the Creative Commons license and indicate if changes were made.

The images or other third party material in this chapter are included in the chapter's Creative Commons license, unless indicated otherwise in a credit line to the material. If material is not included in the chapter's Creative Commons license and your intended use is not permitted by statutory regulation or exceeds the permitted use, you will need to obtain permission directly from the copyright holder.

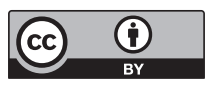

